Research Article

\title{
A System Dynamics Modelling Approach for Electronic Waste Recycling after Floods in Jakarta and New Orleans
}

Ilir Deva ${ }^{1}$, Renata van der Weijden ${ }^{1,2, *}$

1. Environmental Technology, Wageningen University \& Research, P.O. Box 17, 6700 AA, Wageningen, The Netherlands; E-Mails: ilirdeva15@gmail.com; renata.vanderweijden@wur.nl; renata.vanderweijden@wetsus.nl

2. Wetsus, European Centre of Excellence for Sustainable Water Technology, P.O: Box 1113, 8900 CC Leeuwarden, The Netherlands

* Correspondence: Renata van der Weijden; E-Mails: renata.vanderweijden@wur.nl; renata.vanderweijden@wetsus.nl

Academic Editor: Zed Rengel

Special Issue: Solid Waste Treatment

Adv Environ Eng Res

2021, volume 2, issue 4

doi:10.21926/aeer.2104037
Received: October 15, 2021

Accepted: December 09, 2021

Published: December 23, 2021

\begin{abstract}
Due to climate change, flood-related disasters are expected to increase. Floods generate enormous amounts of waste, including electronic waste (e-waste). E-waste should be recovered not only because it can have detrimental effects on human health and the environment but also because of the valuable metals contained in it. In this study, a system dynamics model based on current practices and waste management was established using Vensim to determine the revenue that can be generated by e-waste recycling after floods in two socio-geographic and economic contexts: Jakarta and New Orleans. At current recovery rates, the formal systems employed for recovering valuable materials would yield $8 \%$ (€58 million) and $14 \%$ ( $€ 80$ million) of the potential yield for the Jakarta and New Orleans models, respectively. Moreover, the model estimated that informal e-waste recycling would yield $€ 1.2$ billion. The model also highlighted several problems encountered in post-disaster waste management in both scenarios, such as low capacities of temporary storage sites, increased
\end{abstract}

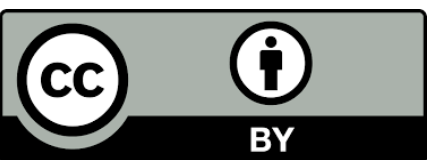

(C) 2021 by the author. This is an open access article distributed under the conditions of the Creative Commons by Attribution License, which permits unrestricted use, distribution, and reproduction in any medium or format, provided the original work is correctly cited. 
landfilling rates, low yields of recovered e-waste components, and limitations on the transportation of waste. For optimizing the recovery of valuable metals, regulations addressing e-waste must be implemented more thoroughly, and post-disaster waste management guidelines must be revised to contextually address flood disasters. When more data are available, an improved model can be established and used as a basis for policymaking to improve the infrastructure of solid waste management to optimize e-waste recovery.

\section{Keywords}

Disaster; waste management; e-waste; floods; system dynamics

\section{Introduction}

The human-environment relationship has often been a volatile one, with several disastrous events that have necessitated extraordinary efforts to maintain the integrity of our settlements [13]. Due to the considerable increase in the population in low-elevation coastal zones, unsustainable development of countries, and in the light of climate change, hydrometeorological disasters such as floods are increasing in frequency and severity [4-7]. Some of the most prominent natural disasters of the 21st century, such as Hurricane Katrina, the 2007 flood in Jakarta, and the Japanese tsunami (2011) have collectively caused the death of tens of thousands of people and extensive damage to property, amounting to a loss of billions of dollars [8]. Furthermore, floods can damage agricultural and water resource systems, alter the ecosystem properties, and induce epidemics; thus, they are a significant global threat [9-11].

Another detrimental consequence of disasters is their contribution to increased waste generation, which is typically 5-15 times the annual waste generation rates of the impacted community [12]. The amount and composition of disaster waste (DW) vary per the scale of the disaster and the type of built environment impacted $[13,14]$.

The research on the implications of e-waste generation following flood disasters is scant. As one of the fastest and dangerous growing waste streams worldwide, with nearly three times faster growth than municipal solid waste (MSW), electronic waste (e-waste) presents a significant threat to the livelihood of individuals, groups, and ecosystems $[15,16]$. Therefore, the removal and recovery of e-waste during the flood debris removal process should be considered an essential endeavor during post-disaster waste management. E-waste concentrations may be relatively low during a flood; however, the risk associated with the waste stream is considered high because of the potential leaching of hazardous components $[15,16]$. Therefore, context-sensitive flood waste management that addresses the variability of e-waste and its sustainable handling for recovering valuable metals is required.

Several studies have analyzed the solid waste composition and the amount produced by a disaster. For instance, [17] analyzed the specific gravities of the debris following the Great HanshinAwaji earthquake and noted differences in the specific gravity of the DW during transportation and in the stockpile, the latter being heavier due to consolidation processes and water addition for suppressing dust. Another study [18] demonstrated that the amount of debris generated by floods 
in Taiwan can be estimated accurately by using the significant nonlinear correlations between the DW and the population density, total rainfall, and flooded area.

Despite the existing literature on the mitigation stage after floods (Table 1), the applicability of loss estimation studies to post-disaster waste management has not been investigated in detail. However, a few noteworthy studies have addressed this relationship. In [19], loss estimation and post-disaster waste management were quantitatively integrated using a combination of a geographical information system (ArcGIS), an earthquake estimation tool (ELER), and an evolutionary multi-objective optimization technique (NSGA-II). In another study [20], a multiobjective linear programming DW reverse logistic model was established that considered the objectives of minimization of economic cost, risk penalty, and psychological stress; the latter being a function of waiting time for debris removal, access to medical treatment and distress from relocation and destruction of residents' homes.

Table 1 Stages of disaster management preceding and following a disaster.

\begin{tabular}{|c|c|c|c|c|}
\hline & Stage & Description & Estimated Timeline & Sources \\
\hline 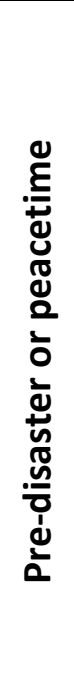 & Preparedness/Mitigation & $\begin{array}{l}\text { Conducting research and } \\
\text { establishing post-disaster } \\
\text { recovery guidelines } \\
\text { Pre-disaster identification } \\
\text { of temporary storage sites } \\
\text { (TSSs) } \\
\text { Applying mitigation } \\
\text { measures depending on } \\
\text { previous events in specific } \\
\text { regions } \\
\text { Generate risk maps and loss } \\
\text { estimations due to }\end{array}$ & N/A & $\begin{array}{l}{\left[\begin{array}{l}1,14, \\
21]\end{array}\right.} \\
\end{array}$ \\
\hline 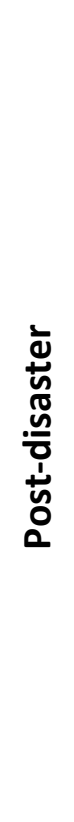 & Emergency Response & $\begin{array}{l}\text { disasters } \\
\text { Debris management to } \\
\text { preserve life, provide } \\
\text { emergency services, and } \\
\text { remove immediate public } \\
\text { health threats such as } \\
\text { hazardous materials and } \\
\text { unstable buildings } \\
\text { Transportation of DW to } \\
\text { TSSs, recovery of reusable } \\
\text { and recyclable materials } \\
\text { from DW, placement of } \\
\text { TSSs, disposal of } \\
\text { nonrecyclable and } \\
\text { hazardous DW, and }\end{array}$ & $\begin{array}{l}\text { A few days to several } \\
\text { weeks, depending on } \\
\text { the scale of the } \\
\text { disaster and the } \\
\text { response rate of the } \\
\text { local authorities }\end{array}$ & {$[12,22,23]$} \\
\hline
\end{tabular}




\author{
incorporation of DW into \\ rebuilding \\ DW conversion to energy
}

\begin{abstract}
Can have a duration of up to 10 years, depending on the scale of the disaster and the response rate

of the local authorities

Rebuilding waste generated from and used in reconstruction
\end{abstract}

[24]

Note: Emergency response occurs first, whereas recovery and rebuilding may overlap.

Furthermore, [25] introduced a multi-objective mathematical model for processing DW in a postdisaster scenario for optimizing the financial cost, environmental cost, landfill utilization, and revenue from recycled debris. In [26], a decision support system for DWM was developed by proposing a linear programming model to minimize the DW processing costs and maximize the revenue generated by DW recycling. Lastly, [5] established a multi-objective mixed-integer linear programming model to address the problem of supply chain network design associated with DW processing while considering economic, environmental, and social objectives. Moreover, the model developed in [5] allows various loss estimation methods to be incorporated, thereby extending its application to several disasters. Most models ignore potential illegal activities associated with DWM; these issues are problematic in the context of DWM, especially in developing countries.

Despite the extensive research on loss estimation tools, studies remain generalized; moreover, limited tools are available to assess the damage. For instance, while GIS technology has been widely used to estimate the amount of debris, its accuracy is hindered by the difficulty in distinguishing between shadows of collapsed buildings, trees, and other urban features surrounding the impacted environment [27]. This, in turn, leads to over-or under-estimation of the amount of debris, which increases the costs associated with handling the debris $[12,27]$. These costs may be exacerbated for waste streams such as e-waste, which require specific and expensive treatment techniques [28].

The main objectives of this paper are to use the Vensim system dynamics modeling engine to analyze disaster e-waste management practices after floods and estimate the valuable metal output and the associated potential revenue of the recovered e-waste valuable metal output. From this modeling, the obstacles encountered in optimum recovery become apparent. The model focused on two socio-geographical settings with similar flood events, namely Jakarta and New Orleans. It incorporated local e-waste management practices, routes of post-disaster waste management based on relevant guidelines, and flood-related variables impacting transportation. The system dynamics model can be considered as a "skeleton code," which can be modified for a sociogeographic setting and waste stream. Besides the formal waste management addressed in other studies, informal waste management and transportation logistics were also included in this study. 


\section{Materials and Methods}

\subsection{Literature Review}

The methodology of the current study involved an investigation of secondary sources, accessible via the Wageningen University and Research Library, Web of Science, Scopus, Google Scholar, governmental websites and reports, as well as news articles regarding flood-related events in the two socio-geographic settings. Information derived from the literature review served as the building blocks of the system dynamics modeling approach.

The following keywords were used in the literature search: "disaster waste management," "flood debris," "Hurricane Katrina," "2007 Jakarta floods," “New Orleans," “Jakarta," "e-waste management," "formal e-waste recycling," "municipal solid waste," "informal e-waste recycling," "flood depth," "disaster waste estimation method," and "temporary storage site." A number of these keywords were combined to obtain data pertaining to the socio-geographic setting. Examples of useful search combinations include "e-waste management in Jakarta" and "flood debris management post Hurricane Katrina."

The data acquired for the given project originated from scientific publications, governmental reports and databases of disasters, intergovernmental reports and guidelines regarding postdisaster recovery processes, and newspaper articles.

The selection of the cases was based on the countries' similar regulatory framework with regards to e-waste, their analogous degree of flood risk due to land subsidence and climate change, and similar past experiences with chronic and flash flooding. In addition, flooding in these two cases was relatively more well-documented in the literature and news reports.

\subsection{System Dynamics Model}

\subsubsection{Model Design and Feedback Loop Diagram}

To express the system's approach in the current project, the simulation software Vensim Personal Learning Edition (Ventana Systems) was used. Vensim, similar to other simulation software tools such as STELLA, DYNAMO, and POWERSIM, provides a set of graphical objects with integrated mathematical functions to easily represent a system structure in a simulation model. Another advantage is that the models created using Vensim can be modified easily and are easily understood and accessible by a wide audience of stakeholders in the systems being modeled.

For developing a system's dynamics model, the causal or feedback loops must be identified for analyzing which part of the system could cause a particular pattern of behavior. The design of the model is based on numerous flowsheets that have been proposed as guidelines for DW management and e-waste management [22, 29-32]. DW management guidelines emphasize four stages of disaster management planning: mitigation, emergency response, recovery, and rebuilding $[1,12,19,22]$. These stages are briefly summarized in Table 1.

In the current model, because the focus of the project is on e-waste and material output, the main flux of the system is the waste material/debris expressed in kilograms of waste/e-waste per unit of time. A simple feedback loop diagram (Figure 1) was mapped to serve as a basis for the design of the model. 


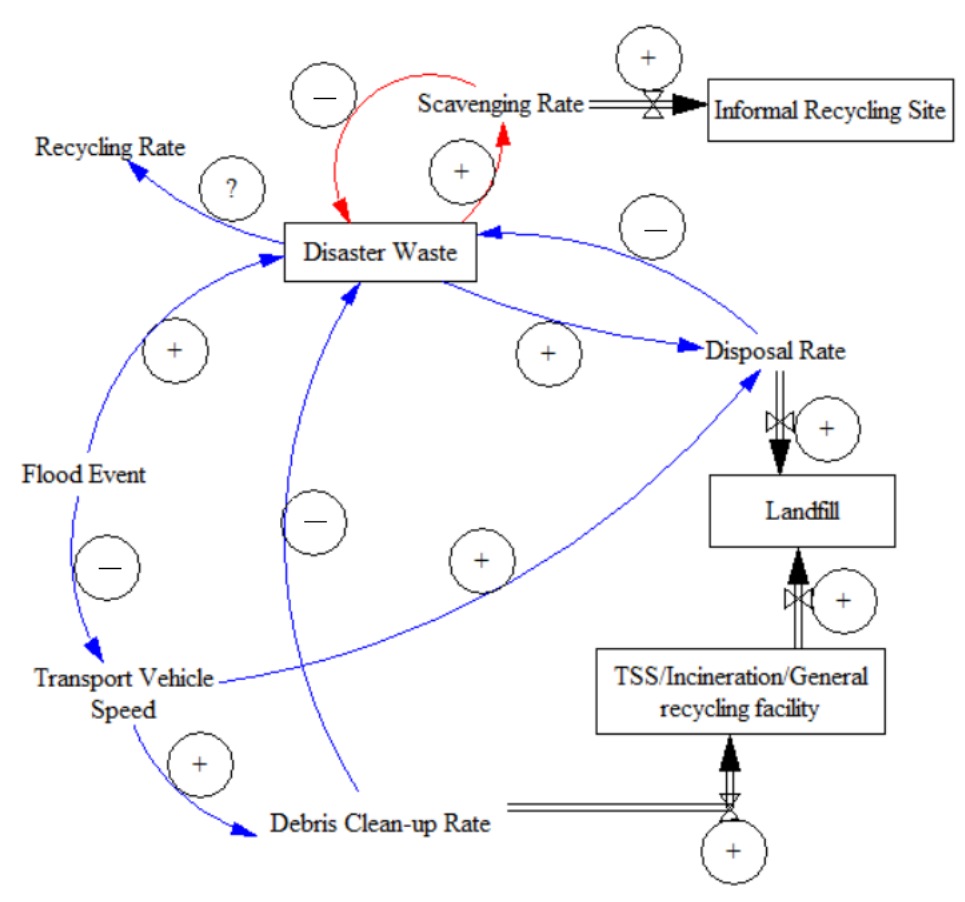

Figure 1 Feedback loop diagram indicating the impact of flooding on the determinants of a built-in waste management system.

The circles with a "+" denote a positive or reinforcing feedback, the circles with a "-" denote a negative or balancing feedback, and the circles with a "?" indicate an ambivalent or questionable relationship.

The diagram demonstrates the impact of a flood event on a waste management system. Initially, the flood event generates DW, some of which will warrant disposal. The higher the generation of DW, the greater the tendency to dispose it in a landfill. Higher disposal rates result in a negative feedback loop. A large portion of DW is first transferred to designated temporary storage sites (TSSs) to be separated. It is then treated further in an incineration or recycling facility. This debris cleanup rate negatively correlates with the amount of debris present in the area. However, the flood event can indirectly impact both the disposal rate and debris clean-up rate by affecting the vehicle speed and hindering transfer services. This relationship is expected in a disaster setting; therefore, careful consideration of the types and the availability of debris transportation vehicles in a system's approach is required. In addition, most disaster events present opportunities for illegal looting and scavenging of waste [33]. The diagram shows that scavenging increases with the amount of DW, thus contributing to the accumulation of waste in informal treatment sites. Moreover, some relationships within the diagram are not clearly defined due to being contextually dependent, thus yielding ambivalent results. For instance, depending on the scale of the disaster, the composition of the debris, transfer rates, and whether the recycling facilities are found within the inundation zone, disaster events may expedite or hinder the recycling rate $[12,34]$. In the current project, only the impact of flooding on the transfer rate of waste was considered as a changeable variable, whereas for the recycling rate-the model, constant and contextually relevant peacetime recycling rates were assumed for the material yield. 


\subsubsection{Model Simulation}

The model considers a hypothetical flood scenario caused by a major hydrometeorological event, for instance, a typhoon or hurricane similar to Hurricane Katrina. The estimates of the debris generated were considered as a range, which is typically 5-15 times the MSW generation of a given community [12]. By using Jakarta's and New Orleans's respective population and annual waste generation per capita, the amount of waste generated from this hypothetical flood was calculated as five times the annual waste generation of each city. The lower bound of the range was set to include waste volumes similar to that generated by Hurricane Katrina. The potential resulting waste generated would be 1.59 and 15.7 billion kg for New Orleans and Jakarta, respectively.

The model has a runtime of 5 years or 1825 days, with time-steps of 1 day. The lengthened duration of the recovery phase, in this case, follows the duration of Hurricane Katrina's recovery phase, which lasted up to 5 years [12]. Vensim can integrate the values of the levels by using Euler's integration method. Subsequently, all levels have an integration function that integrates all incoming and outgoing rates and calculates the amount accumulated across the 1825 days. The design of the two models is shown in Figures S1 and S2.

\subsubsection{Model Assumptions}

Due to the tremendous amount of waste generated by the hypothetical disaster event, the model assumes that the amount of debris is too large for on-site waste separation. Thus, off-site waste separation is performed at designated TSSs. These sites are assumed to collectively have a volume of 1 million cubic yards. Based on different MSW densities in both settings, this is equivalent to $764,555 \mathrm{~m}^{3}$ or 321 million $\mathrm{kg}$ for the US and 287 million $\mathrm{kg}$ for Indonesia, given 100 acres of land [35-37]. This can be understood as multiple TSSs located within a radius of $2 \mathrm{~km}$ from the debris area.

The model assumes that sufficient financial resources are available to successfully perform TSS selection and debris allocation operations. For debris management operations, such as collection, transportation, and the installation of the TSS facility, millions of dollars are required. This assumption ensures that sufficient donations or government funds are available to smoothly perform all response-phase waste-management operations.

The transfer rate between the facilities is assumed to be unimodal. The transfer is carried out using trucks, each with specific speeds and carrying capacities. In addition, the transfer rates are dependent on several auxiliary variables, which carry context-specific values. These variables include the distance from one facility to another (in $\mathrm{km}$ ), the speed of the trucks (in $\mathrm{km} / \mathrm{h}$; maximum: $40 \mathrm{~km} / \mathrm{h}$ ), the carrying capacities of the trucks (in $\mathrm{m}^{3}$, converted to $\mathrm{kg}$ by considering the MSW densities for each country), the number of trips done per day (250 for New Orleans and 450 for Jakarta), and the rates of (e-)waste recycling/incineration/landfilling per respective country (\% $\mathrm{kg} /$ day). The carrying capacities of the trucks for New Orleans and Jakarta were $9962 \mathrm{~kg}$ [38] and $9150 \mathrm{~kg}$ [39], respectively. Due to lack of data correlating transport trips for clean-up operations and waste generation, an arbitrary number of trips, specifically 450 per day, was taken for clean-up operations in the case of Jakarta. This number is reduced to 225 in the case of New Orleans, as a result of differences in population, area, and waste generation. 
Moreover, a 4-m flood depth, which decreases at a constant rate of $0.1 \mathrm{~m} /$ day over the span of 40 days, is assumed. This assumption is based on the actual dewatering time span of the flooding following Hurricane Katrina [40]. For this reason, a flood-depth disruption equation (Eq. (1)) was included in the model to simulate the inhibition of the transfer rate due to the flood depth [41]:

$$
v(w)=0.0009 w^{2}-0.5529 w+86.9448
$$

where $v(w)$ is the maximum acceptable velocity and $w$ is the flood depth.

According to [42], a distance of $2 \mathrm{~km}$ from the debris area is a safe and economical distance for establishing a TSS; greater distances would increase transportation costs significantly. The distance from the TSS to other facilities was calculated separately for the two settings. For the New Orleans model, an ArcGIS disaster debris recovery tool developed by the USEPA was utilized to identify available facilities within the State of Louisiana. The results were screened for landfills and recovery and recycling facilities treating metal, e-waste, construction and demolition (C\&D) waste, and vegetative debris. The distance to these facilities was calculated from the center of New Orleans and resulted in an average of $290 \mathrm{~km}$ across the entirety of Louisiana. Because $80 \%$ of the city was inundated following Hurricane Katrina, any facility found within the inundated area was omitted from the distance calculation.

In the case of Jakarta, the distance from the TSS to the facilities was calculated using the available data of e-waste facilities and some landfills located within West and Central Java. Due to the lack of data, only a limited number of facilities could be identified. These facilities include six metal recovery facilities, six smelters and e-waste collector locations, and seven landfills found in a 600$\mathrm{km}$ radius from the center of Jakarta to the rest of Java island [31, 43-45]. The average distance from the TSS to these facilities is $163 \mathrm{~km}$.

The e-waste recycling in both settings was assumed to be performed using pyrometallurgical, hydrometallurgical, and magnetic and eddy current separators. In addition, an informal e-waste recycling treatment was considered for the Indonesian model, which involved rudimentary practices such as open burning, acid baths, and the use of chisels and hammers for metal separation and recovery. The yields of these facilities/sites were separated into five categories of materials from which e-waste is composed, namely plastics, ferrous (Fe) metals, non-ferrous (non-Fe) metals, precious metals (PMs), and other components (Figure 2). 


\section{Percentage of E-waste Components}

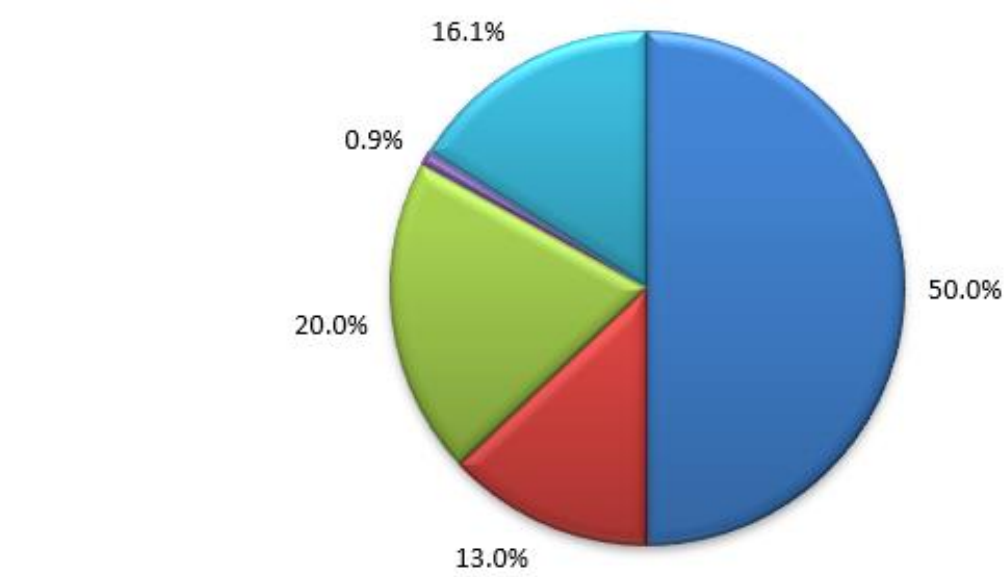

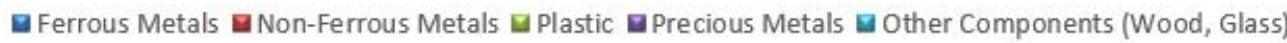

Figure 2 General composition of e-waste from [46].

In both settings, $3 \%$ of the total waste was assumed to be e-waste. This percentage was acquired by calculating the ratio of e-waste to municipal solid waste at the city level for the Jakarta model and at the country level for the New Orleans model. For the New Orleans model, e-waste data at the municipal level was lacking; the true proportion of electronics to other damaged goods during the hypothetical flood scenario may be higher than the calculated ratio. The calculated ratio is assumed as the minimum amount of e-waste generated during the flood event. Given the lack of data and the aim of the current study, the effect on waste composition caused by the simultaneous occurrence of disasters such as the Covid-19 pandemic or cholera is not considered. According to [47], the ratio of e-waste to total waste is highly unlikely to have changed during the Covid-19 pandemic.

The waste removal process is assumed to be homogeneous in the sense that e-waste is not removed during a special episode throughout the post-disaster recovery phase. Average recovery rates for these materials were acquired from the literature and incorporated in the model; $15 \%$ and $7 \%$ of discarded e-waste is recovered formally in the US and Indonesia, respectively [43, 48]. These rates were maximized to $100 \%$ for an ideal full recovery scenario. Specific e-waste recycling rates of the available technologies/practices for acquiring e-waste components are listed in Table 2.

Table 2 E-waste recycling rates incorporated in the models $[28,49,50]$.

\begin{tabular}{lllll}
\hline Models & E-waste management & PM & Non-Fe & Fe \\
\hline New Orleans & Formal & $90 \%$ & $99 \%$ & $100 \%$ \\
\multirow{2}{*}{ Jakarta } & & & & \\
& Informal & $15 \%$ & $30 \%-40 \%$ & $30 \%-40 \%$ \\
\hline
\end{tabular}


Scavenging is assumed to be the main activity in the e-waste transfer to an informal recycling site in the Jakarta model. According to [51], scavengers play an essential role in recovering and/or recycling waste in Jakarta, where formal MSW management is not present. The material transfer (in $\mathrm{kg} /$ day) was acquired from the literature on e-waste flows in another city in Indonesia, whereas the number of scavengers was estimated from a newspaper article (Table 3 ).

Table 3 Known parameters for informal waste management pathways.

\begin{tabular}{lll}
\hline & Description & Source \\
\hline & $\begin{array}{l}\text { The average collection rate of scavengers is 20.3-32.5 } \\
\mathrm{kg} / \text { day, derived from an article mapping e-waste flows } \\
\text { in Yogyakarta. The average of the range was inserted } \\
\text { in the corresponding variable in the model (Table S2). }\end{array}$ & \\
Scavenging rate & $\begin{array}{l}\text { Approximately 25,000 scavengers in Jakarta help } \\
\text { Number } \\
\text { scavengers }\end{array}$ & reduce waste under the radar.
\end{tabular}

\section{Results}

The results of the study are discussed separately for Jakarta and New Orleans, allowing us to address the model results contextually given each city's social, geographical, and economic characteristics.

\subsection{Jakarta Hypothetical Flooding Case Study}

Jakarta's susceptibility to floods is attributed to numerous physical and socio-economic factors [53]. As a coastal city in the era of climate change, Jakarta faces an unprecedented threat due to accelerated sea-level rise and subsidence [54]. The current subsidence rate of the city is approximately 1-25 cm/year [55]. This is driven by unsustainable anthropogenic activities such as groundwater extraction and construction loads, natural consolidation of alluvium soil, and geotectonic changes, coupled with an inhibited drainage capacity of channels due to sediment and solid waste clogging. These major physical determinants have contributed to Jakarta's chronic flooding problem [55-57]. The rate of sea-level rise in Jakarta is increasing at over $1 \mathrm{~cm} /$ year [58]. Globally, sea-level rise is estimated to reach $0.39-0.84 \mathrm{~m}$ by 2100 [59]. These factors have resulted in floods such as the one in 2007, which was particularly devastating as it caused the death of 79 individuals, the displacement of 422,000 people, and the destruction of 1500 homes, with economic losses estimated at US\$695 million [60-62].

E-waste is poorly defined within the Indonesian Government's regulatory framework because it is regulated as part of hazardous and toxic waste [31]. While e-waste may constitute hazardous components, assigning alternative definitions different from those used in the EU-WEEE directive makes the management of the waste stream difficult and facilitates informal pathways for treatment [30, 31]. As a result, there are few licensed recycling companies in Indonesia, leading to the improper disposal of most e-waste. Approximately 60 tons of industrial e-waste are collected 
annually in a CRT facility; this includes products such as CRT TVs/monitors, LCD TVs/monitors, washing machines, personal computers, digital cameras, and printers [16].

Multiple studies have noted that Indonesia has a complex web of informal e-waste management, which accounts for a major portion of the e-waste being processed [50, 63, 64]. This informal pathway is a significant sink with respect to the formal e-waste management sector during peacetime conditions; for this reason, there is little e-waste to be found in Indonesian landfills [64]. However, due to its illegal nature, this unofficial e-waste management system circumvents environmental and health regulations, facilitates detrimental work conditions, and deteriorates the environment surrounding the informal recycling sites.

\subsubsection{Model Outcomes Jakarta}

The model demonstrates that in the event of a typhoon at the scale of Hurricane Katrina, there would be a significant amount of debris even after a time period of 5 years (approximately 8.7 billion $\mathrm{kg}$ left in the impacted area) (Figure 3). Several factors delay the removal, including the limited space in the TSS (the model shows that the TSS overloads within 67 days) and the flood depth (which disrupts the speed of the vehicles in the first 40 days).

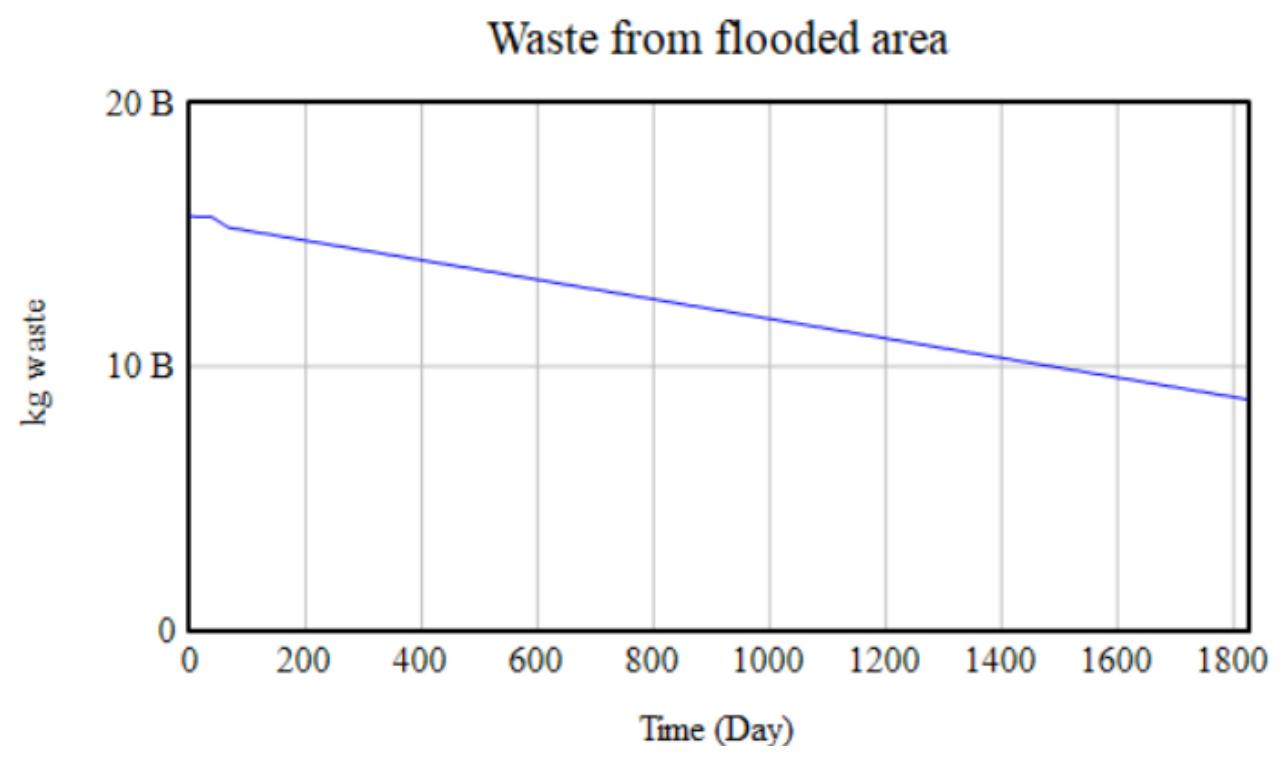

Figure 3 Model output regarding the total waste in the flooded area in Jakarta after 5 years. "B" represents billion.

The material output from the formal e-waste recycling facility ranges from 2086 to $128,790 \mathrm{~kg}$ for the different categories of e-waste components, whereas for the informal site, the material output ranges from 45,074 to 5,008,240 kg. This is shown graphically in Figure 4. 


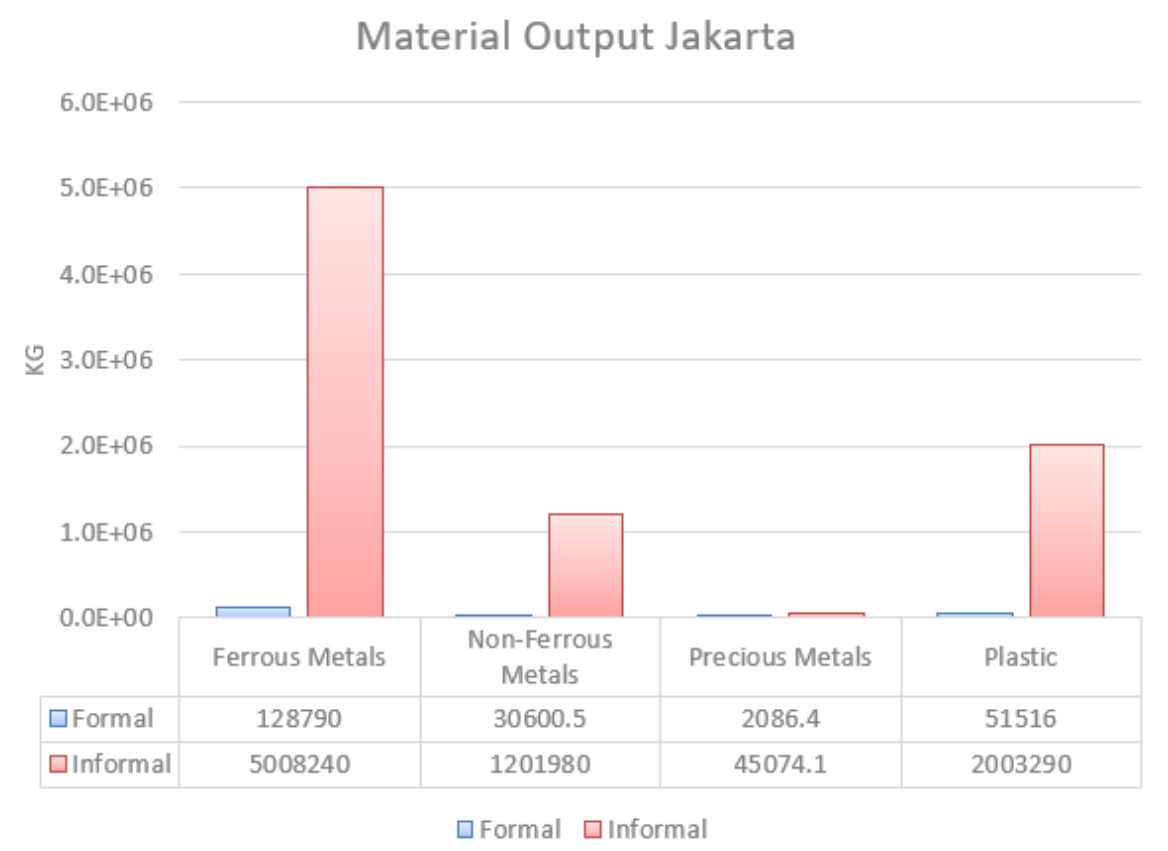

Figure 4 Model results for material yields of Jakarta on day 1825.

Based on the current prices of materials (Fe: $€ 0.1 / \mathrm{kg}$, Non-Fe: $€ 4 / \mathrm{kg}, \mathrm{PM}: € 28,000 / \mathrm{kg}$, and plastic: $€ 0.05 / \mathrm{kg}[16,65,66])$, approximately $€ 58$ million and $€ 1.2$ billion net worth of materials can be recovered formally and informally, respectively. Accordingly, formal and informal recycling would compensate for $0.16 \%$ and $3.44 \%$ of the total economic losses, assuming the hypothetical flood scenario has similar disaster costs as Hurricane Katrina, that is, approximately $€ 36.7$ billion [67].

The full recovery (100\%) scenario would amount to $€ 730$ million worth of e-waste components for formal recycling. Therefore, current recycling rates represent $8 \%$ of the total potential yield; consequently, $2 \%$ of total disaster costs would be offset.

\subsection{New Orleans Case Study}

The factors affecting the risk of flooding in New Orleans are as diverse, heterogeneous, and uneven as those for the coast of Jakarta. Natural sediment deposition and production of organic soil in wetland vegetations have been disrupted by human settlements, levee construction, and coastal defense establishments, which were installed for serving the city's economy and population. Moreover, studies on the coast of New Orleans have noted several anthropogenic drivers of subsidence, such as groundwater, oil and gas extraction, compaction of aquifers, mining and fluid withdrawal, and drainage projects inducing organic sediment decomposition and compaction [68]. Due to the complexity of the factors driving subsidence, areas in New Orleans are subsiding at varying rates ranging from $<0.2$ to $40 \mathrm{~mm} /$ year [68].

Debris management in Louisiana is regulated in a more extensive manner than in the case of Jakarta. The State Department of Environmental Quality has prepared a comprehensive debris clean-up and management plan that emphasizes the various categories of waste associated with prominent disasters in Louisiana and how to treat such waste [69]. The plan includes definitions of different waste streams, various categories of disasters and associated responses, requirements for establishing a TSS, detailed disposal and treatment options, and administrative forms for proper 
documentation of the debris removal process. With regard to e-waste management, Louisiana provides its residents with a list of drop-off locations for e-waste in different areas across the state [70]. Moreover, the comprehensive plan specifies how e-waste should be handled by the relevant state agencies.

Following Hurricane Katrina, the recycling of e-waste was greatly hindered due to the extensive damage to the appliances by the floodwater. According to the disaster debris removal after Katrina report by Congress, 602,711 units of electronic goods were collected in Louisiana for treatment [71]. Nonetheless, recycling of e-waste after Hurricane Katrina was considered to be one of the most successful endeavors of e-waste recovery following a disaster as the US Army Corps of Engineers and private companies Dell and Best Buy recycled over 12,500 tons of e-waste [16].

In contrast to the case of Jakarta, little information is available regarding the existence of an informal e-waste management web in the city of New Orleans or the state of Louisiana. For this reason, this recycling pathway was not introduced for the New Orleans model.

\subsubsection{Model Outcomes New Orleans}

In the hypothetical hurricane-induced flood scenario, New Orleans would be devastated by the generation of large amounts of waste, disruption of transportation due to a high flood depth, and other hazards associated with the event (Figure 5). After 40 days of dewatering, the debris transfer to the TSS is observed to be smooth until day 86, at which the TSS reaches maximum capacity. Following the debris disruption transfer due to max capacity, the debris is gradually discharged until the clean-up reaches its endpoint at day 1154 (or after 3.2 years). Nonetheless, due to the slower waste management operations, the TSS remains occupied by the flood debris and is completely emptied on day 1446 (i.e., almost 4 years since the flood event).

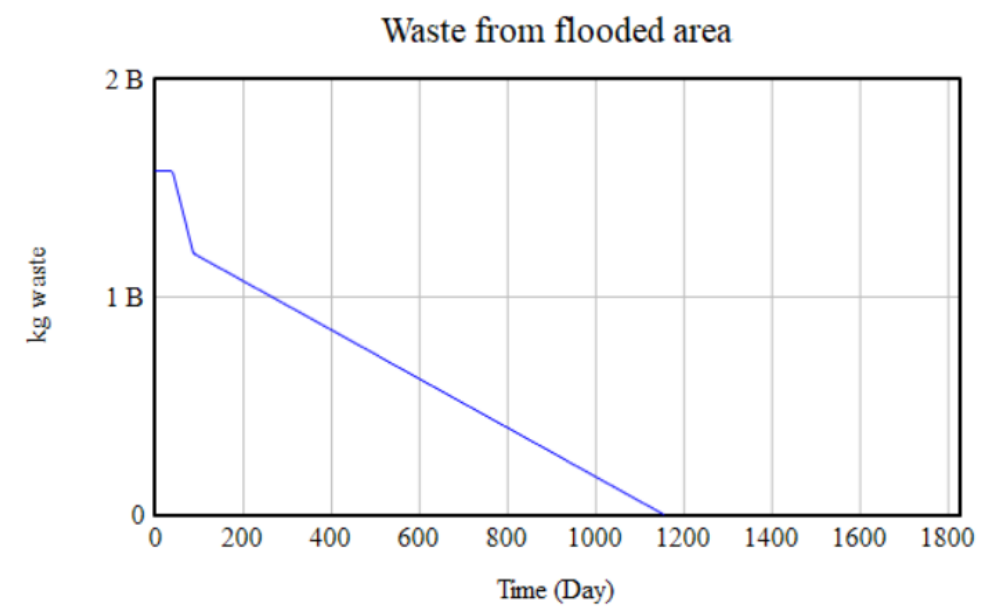

Figure 5 Model output for the total waste in the flooded area in New Orleans after 5 years; "B" represents billion.

With regards to the e-waste management in the New Orleans model, the amount of discharged material was similar to that of the Jakarta model. The potential material yield of the model in terms of valuable e-waste materials is shown in Figure 6; the material output is higher compared to the Jakarta model's formal material yield. In terms of revenue gains, formal recycling in New Orleans would yield approximately $€ 80$ million, accounting for $0.22 \%$ of total disaster costs. The higher yield 
comes as a result of the US's greater e-waste recycling rate; however, it is still significantly lower than that of Jakarta's informal pathway. The full recovery scenario yielded $€ 576$ million worth of ewaste components for formal recycling. Thus, $14 \%$ of the total potential yield is recovered at current recovery rates. For full recovery conditions, total disaster costs would be offset by $1.5 \%$.

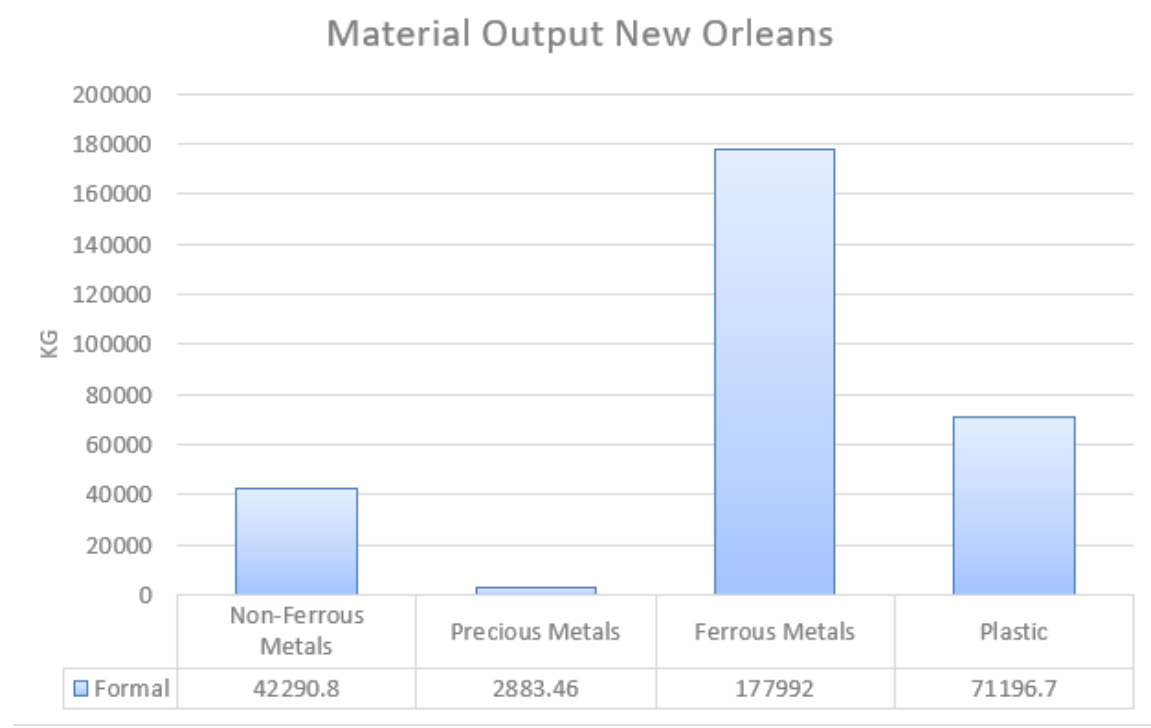

Figure 6 Model results for material yields of the New Orleans's model at day 1825.

\section{Discussion}

The resulting debris ( 15.7 billion $\mathrm{kg}$ ) from the Jakarta model is deemed relatively high; however, there are some uncertainties. First, given that the model uses linear equations, the debris removal rate is linear. However, the DW removal rate may not follow a linear pattern. For instance, the rate can increase exponentially when more of the affected area can be accessed with time and assuming adequate capacity of TSSs and recycling facilities. Second, the unimodal transportation (usage of trucks) hinders the debris removal process in the first 40 days, which may not reflect real-life situations as local governments may be incentivized to utilize cargo ships and airplanes to expedite the DW removal process. Third, the impact of scavengers remains unknown because of the dearth of data regarding their activities. Nonetheless, scavengers serve as a great sink for the formal ewaste recycling processes, especially because their activities are assumed to be unaffected by the flood depth. Lastly, the DW transfer from the flooded area is hindered by the amount of waste that can be stored in TSSs.

For Jakarta, the waste estimate was tenfold greater than that of New Orleans because of the immense population difference and the size of the cities. Waste estimation must be performed when considering a revision of the current model input by utilizing the repository on DW estimation methods; in addition, known approaches addressing floods and e-waste such as that in [16] can be included. In the current project, a basic approach was used for estimating the amount of waste produced, which may present the problem of debris over-or under-estimation when allocating efforts and funding to clean up the debris. This would lead to additional costs associated with the DW management. Consequently, additional tools, such as mathematical models or GIS, must be employed to more accurately assess the amount of DW produced. 
Due to a significant amount of debris generation, the local authorities may opt for direct transportation of DW to landfills and incineration facilities rather than establishing TSSs for separation purposes. However, due to Indonesia's crisis with municipal solid waste and the overflow of landfills, this may pose a significant challenge to the environment [45].

In both settings, transportation was considered unimodal and depended on factors such as speed of the vehicles, carrying capacity, and number of trips or vehicles used. When assuming an equivalent amount of trucks being used in both models, the results showed that the material output halved in the Jakarta case, thus highlighting Jakarta's poorer post-disaster waste management capabilities.

The model reveals that formal recycling yields less recoverable materials than informal recycling. This can be attributed to the more complex pathway associated with formal e-waste in comparison to informal e-waste. In the first 40 days of the run, there is no inflow of e-waste to the formal recycling facilities due to transportation being obstructed by the flood depth. At day 40, the maximum transportation speed can be reached, after which the flow to and from the facility is constant. Moreover, a significant portion of the e-waste formally flowing from the debris area discharges into landfills due to the high landfilling rate in Indonesia. In contrast, the materials acquired by scavengers do not discharge into a landfill; instead, they arrive at informal recycling sites.

Overall, the limited recovery of materials can be attributed to the limited number of formal recycling facilities in the nearby surrounding region, that is, Western and Central Java. Thus, distance plays a significant limiting role in the transportation of e-waste to relevant facilities. Nonetheless, not much is known with regard to transportation logistics within the informal e-waste management pathway. This lack of information may be a factor to be considered in future models because the current model only represents the transportation rates in fractions of inflows and outflows.

In the case of New Orleans, due to its lower population count and density and a large number of recycling sites, landfills, and other waste management facilities, the debris is removed much faster relative to the case of Jakarta. Due to the differences in the densities of MSW in the two scenarios, the New Orleans TSS can hold a higher amount of debris (in kg) than the TSS of the Jakarta model.

Furthermore, e-waste material recovery rates are shown as functions of transfer rates (inflow to the facility/site), with additional assumed recovery rates for each pathway based on known metallurgical techniques. The overall recovery rate is low despite the tremendous amount of debris produced by the flood event ( 1.6 billion $\mathrm{kg}$ ). This is caused by the estimate of e-waste at $3 \%$ in the general waste stream. An analysis of the number of households in the flooded area and their respective e-waste stock can yield a more accurate estimate of the e-waste generated in a flood event. Such an approach [16] is recommended for more reliable estimates.

The full recovery $(100 \%)$ scenario reveals that $8 \%$ and $14 \%$ of the total potential revenue is generated in Jakarta and New Orleans, respectively, assuming current recycling rates.

When compared to the actual post-Katrina situation, e-waste recycling in the model is obtained as significantly lower than the 12.5 million $\mathbf{k g}$ of e-waste that was recycled by private companies. This is because the intervention by private companies was not included in the model because of a lack of quantitative data. Furthermore, the transfer of waste for treatment beyond Louisiana and the debris generated in the entire area impacted by Hurricane Katrina were not considered in the 
model; the model considered the debris for only New Orleans', whereas Katrina impacted three states, namely Louisiana, Alabama, and Mississippi.

\section{Conclusion}

In this study, a model was introduced for analyzing the potential yields of valuable e-waste materials from floods. The system dynamics approach enabled the identification of multiple factors affecting e-waste recovery, such as the socio-economic situation, the degree of formal versus informal recycling, the dewatering rate of the area in relation to transportation, and the number of and distance to TSSs and recycling facilities. Therefore, despite the uncertainties and lack of data, the model is a good starting point in predicting how e-waste recovery in a post-flood context can be optimized.

The results of this model can be used to determine bottlenecks and optimize the following key aspects of DWM: 1 ) the timely removal of waste to reduce the impact on the environment and public health, 2) the timely separation of waste streams to remove toxic fumes at dumpsites and TSSs, 3) and the generation of cost-offsetting revenues by bringing waste metals back into the resource cycles.

Comparison of waste management pathways in two socio-economic scenarios highlighted the importance of informal actors in the recycling and recovery effort. Although informal recycling activities contribute greatly to environmental and public health issues, they result in a higher material gain compared to mere formal recycling efforts. The population density and size of the region play an important role in the recovery phase as it is more difficult to establish TSSs in more densely populated areas.

Furthermore, the impact of external factors on the model, such as climate change or combinations of disasters, are considered beyond the scope of this research. However, these factors can be included in future studies. For instance, calculating the global warming potential of e-waste and incorporating the environmental and economic benefits of GHG reduction as a consequence of increased e-waste recycling will help improve the understanding of the model's impact on climate change mitigation. With the progression of the COVID-19 pandemic, more data highlighting the pandemic's impact on various socio-technical systems are becoming available. However, further research is required before this impact can be quantified and included in the current model.

DWM is highly context-specific and disaster-specific, and because of its unpredictable nature, standardization is challenging. With the exponential growth of e-waste and floods, it is important to prepare for worst-case scenarios, use models to gain insight into recovery operations, turn crises into material gain opportunities, and adapt to circular economy approaches in the face of disasters.

Policymakers and businesses can employ such models to adapt DWM strategies, thus facilitating speedy debris recovery and higher material and financial gains and minimizing the detrimental impact of e-waste and other hazardous waste on the environment. Future implementations of the model may be able to identify other types of bottlenecks and priorities for improvements associated with DWM. 


\section{List of Abbreviations}

$\begin{array}{ll}\text { Abbreviation } & \text { Meaning } \\ \text { ArcGIS } & \text { Arc Geographical Information System } \\ \text { C\&D } & \text { Construction \& Demolition } \\ \text { CRT } & \text { Cathode-Ray Tube } \\ \text { DW } & \text { Disaster Waste } \\ \text { DWM } & \text { Disaster Waste Management } \\ \text { Fe } & \text { Ferrous Metals } \\ \text { GHG } & \text { Greenhouse Gases } \\ \text { MSW } & \text { Municipal Solid Waste } \\ \text { Non-Fe } & \text { Non-Ferrous Metals } \\ \text { PM } & \text { Precious Metals } \\ \text { TSS } & \text { Temporary Storage Sites } \\ \text { USEPA } & \text { United States Environmental Protection Agency } \\ \text { Vensim PLE } & \text { Vensim Personal Learning Edition } \\ \text { WEEE } & \text { Waste from Electrical and Electronic Equipment }\end{array}$

\section{Acknowledgement}

We thank Dr. Joseph Resovsky MSc., Dr. Jason Dinse, and Christine Leedy B.A. from University College Roosevelt for proofreading the manuscript and providing suggestion of improving the language and the style of the manuscript. We also thank the journal for providing language polishing.

\section{Additional Materials}

The following additional materials accompany the online version of this paper.

1. Figure S1: Model Design for the Jakarta case.

2. Figure S2: Model Design for the New Orleans context.

3. Table S1: List of Equations for the Jakarta model.

4. Table S2: List of Equations for the New Orleans model.

\section{Author Contributions}

The first author, Ilir Deva, provided the research for the project, designed and simulated the model in Vensim and wrote the majority of the paper, as part of the Master Thesis requirement at Wageningen University \& Research. The corresponding author, Dr Renata van der Weijden, introduced the topic, provided supervision and material throughout the writing and research process, and helped with editing the manuscript.

\section{Funding}

This research project required no funding. 


\section{Competing Interests}

The authors have declared that no competing interests exist.

\section{References}

1. US Department of Homeland Security, Federal Emergency Management Agency. Public assistance policy digest. Scotts Valley: Createspace Independent Pub; 2008.

2. Gunn SWA. Multilingual dictionary of disaster medicine and international relief: English, Français, Español. Dordrecht: Kluwer Academic Publishers; 2012.

3. Young S, Balluz L, Malilay J. Natural and technologic hazardous material releases during and after natural disasters: A review. Sci Total Environ. 2004; 322: 3-20.

4. Dwirahmadi F, Rutherford S, Phung D, Chu C. Understanding the operational concept of a floodresilient urban community in Jakarta, Indonesia, from the perspectives of disaster risk reduction, climate change adaptation and development agencies. Int J Environ Res Public Health. 2019; 16: 3993.

5. Habib MS, Sarkar B, Tayyab M, Saleem MW, Hussain A, Ullah M, et al. Large-scale disaster waste management under uncertain environment. J Clean Prod. 2019; 212: 200-222.

6. Merkens JL, Reimann L, Hinkel J, Vafeidis AT. Gridded population projections for the coastal zone under the shared socioeconomic pathways. Glob Planet Change. 2016; 145: 57-66.

7. Neumann B, Vafeidis AT, Zimmermann J, Nicholls RJ. Future coastal population growth and exposure to sea-level rise and coastal flooding-a global assessment. PloS ONE. 2015; 10: e0118571.

8. Camacho-Vallejo JF, González-Rodríguez E, Almaguer FJ, González-Ramírez RG. A bi-level optimization model for aid distribution after the occurrence of a disaster. J Clean Prod. 2015; 105: 134-145.

9. Devkota R, Bhattarai U. Assessment of climate change impact on floods from a techno-social perspective. J Flood Risk Manag. 2018; 11: S186-S196.

10. Paterson DL, Wright H, Harris PN. Health risks of flood disasters. Clin Infect Dis. 2018; 67: 14501454.

11. Zhong S, Yang L, Toloo S, Wang Z, Tong S, Sun X, et al. The long-term physical and psychological health impacts of flooding: A systematic mapping. Sci Total Environ. 2018; 626: 165-194.

12. Brown C, Milke M, Seville E. Disaster waste management: A review article. Waste Manag. 2011; 31: 1085-1098.

13. Reinhart DR, McCreanor PT. Disaster debris management-planning tools. Final report. Washington, DC: US Environmental Protection Agency; 1999.

14. US Environmental Protection Agency. Planning for natural disaster debris. Washington: US Environmental Protection Agency; 2008.

15. Huang J, Nkrumah PN, Anim DO, Mensah E. E-waste disposal effects on the aquatic environment: Accra, Ghana. Rev Environ Contam Toxicol. 2014; 229: 19-34.

16. Leader A, Gaustad G, Tomaszewski B, Babbitt CW. The consequences of electronic waste postdisaster: A case study of flooding in Bonn, Germany. Sustainability. 2018; 10: 4193.

17. Inoue $M$, Matsufuji $Y$, Yanase R. Waste Management and countermeasures of earthquake disaster in Kobe City Japan. Proceedings of the 11th International Waste Management and 
Landfill Symposium Sardinia 2007; 2007 October 1st-5th; Cagliari, Italy.

18. Chen JR, Tsai HY, Hsu PC, Shen CC. Estimation of waste generation from floods. Waste Manag. 2007; 27: 1717-1724.

19. Onan K, Ülengin F, Sennaroğlu B. An evolutionary multi-objective optimization approach to disaster waste management: A case study of Istanbul, Turkey. Expert Syst Appl. 2015; 42: 88508857.

20. Hu ZH, Sheu JB. Post-disaster debris reverse logistics management under psychological cost minimization. Transport Res B Meth. 2013; 55: 118-141.

21. Fetter G, Rakes T. Incorporating recycling into post-disaster debris disposal. Socio Econ Plan Sci. 2012; 46: 14-22.

22. Asari M, Sakai Si, Yoshioka T, Tojo Y, Tasaki T, Takigami H, et al. Strategy for separation and treatment of disaster waste: A manual for earthquake and tsunami disaster waste management in Japan. J Mater Cycles Waste Manag. 2013; 15: 290-299.

23. Portugal-Pereira J, Lee L. Economic and environmental benefits of waste-to-energy technologies for debris recovery in disaster-hit Northeast Japan. J Clean Prod. 2016; 112: 4419-4429.

24. Haas JE, Kates RW, Bowden MJ. Reconstruction following disaster. In: Reconstruction following disaster. Cambridge: US The Massachusetts Institute of Technology; 1977.

25. Lorca Á, Çelik M, Ergun Ö, Keskinocak P. A decision-support tool for post-disaster debris operations. Procedia Eng. 2015; 107: 154-167.

26. Boonmee $C$, Arimura $M$, Asada T. Location and allocation optimization for integrated decisions on post-disaster waste supply chain management: On-site and off-site separation for recyclable materials. Int J Disaster Risk Reduct. 2018; 31: 902-917.

27. Zhang F, Cao C, Li C, Liu Y, Huisingh D. A systematic review of recent developments in disaster waste management. J Clean Prod. 2019; 235: 822-840.

28. Ari V. A review of technology of metal recovery from electronic waste. In: E-Waste in transitionfrom pollution to resource. Croatia: IntechOpen; 2016.

29. Damanhuri E. Preliminary identification of E-waste flows in Indonesia and its hazard characteristics. Proceedings of the 3rd Annual Conference of The National Institute of Environmental Studies; 2006 November 18th; Tsukuba, Japan. Tsukuba: National Institute for Environmental Studies.

30. Rochman FF, Ashton WS, Wiharjo MG. E-waste, money and power: Mapping electronic waste flows in Yogyakarta, Indonesia. Environ Dev. 2017; 24: 1-8.

31. Yoshida A, Terazono A, Ballesteros Jr FC, Nguyen DQ, Sukandar S, Kojima M, et al. E-waste recycling processes in Indonesia, the Philippines, and Vietnam: A case study of cathode ray tube TVs and monitors. Resour Conserv Recycl. 2016; 106: 48-58.

32. UNEP, OCHA. Disaster waste management guidelines. Switzerland: The Joint UNEP/OCHA Environment Unit; 2016.

33. Channel NewsAsia. Scavengers descend on post-flood Jakarta garbage [Internet]. Singapore: Channel NewsAsia; 2020 [cited 2021 March 8th]. Available from: https://www.channelnewsasia.com/news/asia/indonesia-jakarta-garbage-waste-floodgatevaluables-tv-fridge-782151.

34. Reckdahl K. How Katrina killed recycling in New Orleans [Internet]. Philadelphia: Next City; 2014 [cited 2021 March 8th]. Available from: https://nextcity.org/daily/entry/how-katrina-killedrecycling-in-new-orleans. 
35. Kim J, Deshmukh A, Hastak M. Selecting a temporary debris management site for effective debris removal. In: The Proceedings of the 10th International Conference of the International Institute for Infrastructure Resilience and Reconstruction. West Lafayette: Purdue University; 2014. pp.214-218.

36. Reddy KR, Hettiarachchi H, Parakalla NS, Gangathulasi J, Bogner JE. Geotechnical properties of fresh municipal solid waste at Orchard Hills Landfill, USA. Waste Manag. 2009; 29: 952-959.

37. Siami L, Sotiyorini T, Janah Nm. Municipal solid waste quantification and characterization in Banyuwangi, Indonesia. Indones J Urban Environ Technol. 2019; 2: 189-200.

38. RouteReady. What you should know about the 4 major types of garbage trucks [Internet]. Tampa: RouteReady; 2019. Available from: https://routereadytrucks.com/blogs/know-4-majortypes-garbage-trucks/.

39. Burhamtoro WA, Bisri M, Soemarno. Model of municipal solid wastes transportation costs type dump truck (case study at the Malang City, Indonesia). Int J Eng Technol. 2013; 13: 34-40.

40. Jonkman SN, Maaskant B, Boyd E, Levitan ML. Loss of life caused by the flooding of New Orleans after Hurricane Katrina: Analysis of the relationship between flood characteristics and mortality. Risk Anal. 2009; 29: 676-698.

41. Pregnolato $M$, Ford A, Wilkinson SM, Dawson RJ. The impact of flooding on road transport: $A$ depth-disruption function. Transp Res D Transp Environ. 2017; 55: 67-81.

42. Cheng C, Thompson RG. Application of boolean logic and GIS for determining suitable locations for temporary disaster waste management sites. Int J Disaster Risk Reduct. 2016; 20: 78-92.

43. Chatterjee S. Role of informal sector for effective EPR [Internet]. Paris: Organisation for Economic Co-operation and Development; 2016. Available from: https://www.oecd.org/environment/waste/Session 2-Part_1-EPR-Role-of-Informal-SectorSandip Chatteriee.pdf.

44. Munawar E, Yunardi Y, Lederer J, Fellner J. The development of landfill operation and management in Indonesia. J Mater Cycles Waste Manag. 2018; 20: 1128-1142.

45. Shuker IGC, Cary Anne. Indonesia-Marine debris hotspot rapid assessment: Synthesis report. Washingtong, DC: World Bank Group; 2018.

46. Nithya $R$, Sivasankari $C$, Thirunavukkarasu A. Electronic waste generation, regulation and metal recovery: A review. Environ Chem Lett. 2021; 19: 1347-1368.

47. Roy P, Mohanty AK, Wagner A, Sharif S, Khalil H, Misra M. Impacts of COVID-19 outbreak on the municipal solid waste management: Now and beyond the pandemic. ACS Environ Au. 2021; 1: 32-45.

48. Forti V, Balde CP, Kuehr R, Bel G. The global E-waste monitor 2020: Quantities, flows and the circular economy potential. Bonn, Geneva and Rotterdam: United Nations University/United Nations Institute for Training and Research, International Telecommunication Union, and International Solid Waste Association; 2020.

49. Ardi R, Handafiah F. Mapping electronic waste flows in depok, west java. In: IOP Conference Series: Earth and environmental science. Bristol: IOP Publishing; 2019. pp.012005.

50. Tesfaye F, Lindberg D, Hamuyuni J, Taskinen P, Hupa L. Improving urban mining practices for optimal recovery of resources from e-waste. Miner Eng. 2017; 111: 209-221.

51. Kurniawan TA, Avtar R, Singh $D$, Xue W, Othman MHD, Hwang GH, et al. Reforming MSWM in Sukunan (Yogjakarta, Indonesia): A case-study of applying a zero-waste approach based on circular economy paradigm. J Clean Prod. 2021; 284: 124775. 
52. Sidiq F. Scavengers work under radar to help reduce waste [Internet]. Jakarta: The Jakarta Post; 2019 [cited 2021 March 8th]. Available from: https://www.thejakartapost.com/news/2019/02/26/scavengers-work-under-radar-to-helpreduce-waste.html.

53. Ward PJ, Marfai MA. Climate adaptation in the city of Jakarta. In: Climate adaptation and flood risk in coastal cities. New York: Routledge; 2013. pp.305-324.

54. Field CB, Barros V, Stocker TF, Dahe Q. Managing the risks of extreme events and disasters to advance climate change adaptation: Special report of the intergovernmental panel on climate change. Cambridge: Cambridge University Press; 2012.

55. Abidin HZ, Andreas H, Gumilar I, Fukuda Y, Pohan YE, Deguchi T. Land subsidence of Jakarta (Indonesia) and its relation with urban development. Nat Hazards. 2011; 59: 1753-1771.

56. Budiyono Y, Aerts J, Brinkman J, Marfai MA, Ward P. Flood risk assessment for delta mega-cities: A case study of Jakarta. Nat Hazards. 2015; 75: 389-413.

57. Takagi H, Esteban M, Mikami T, Fujii D. Projection of coastal floods in 2050 Jakarta. Urban Clim. 2016; 17: 135-145.

58. Padawangi R, Douglass M. Water, water everywhere: Toward participatory solutions to chronic urban flooding in Jakarta. Pac Aff. 2015; 88: 517-550.

59. Pörtner HO, Roberts DC, Masson-Delmotte V, Zhai P, Tignor M, Poloczanska E, et al. The ocean and cryosphere in a changing climate-summary for policymakers [Internet]. Geneva: Intergovernmental Panel on Climate Change; 2019. Available from: https://www.ipcc.ch/site/assets/uploads/sites/3/2019/12/SROCC FullReport FINAL.pdf.

60. Bank W. Keeping Indonesia's capital safer from floods [Internet]. Washington: The World Bank; 2016 [cited 2021 March 10th]. Available from: http://www.worldbank.org/en/news/feature/2016/01/08/keeping-indonesias-capital-saferfrom-floods.

61. Bappenas. Laporan Perkiraan Kerusakan Dan Kerugian Pasca Bencana Banjir Awal Februari Di Wilayah JABODETABEK [Internet]. Jakarta: Ministry of National Development Planning of the Republic of Indonesia; 2007.2 Available from: https://www.bappenas.go.id/files/3713/5462/9576/laporanbanjir $20081123055830 \quad 995 \quad 0 . p d f$.

62. World Health Organization. Floods in Jakarta province, republic of Indonesia. Geneva: World Health Organization; 2007; Emergency Situation Report \# 5.

63. Damanhuri E. Country chapter. State of the 3Rs in Asia and the Pacific [Internet]. Nagoya: United Nations center for Regional Development; 2017. Available from: https://www.uncrd.or.jp/content/documents/6777[full\%20document]\%20State\%20of\%20the \%203Rs\%20in\%20Asia\%20and\%20the\%20Pacific.pdf.

64. Rimantho D, Nasution SR. The Current Status of e-waste management practices in DKI Jakarta. Int J Appl Environ Sci. 2016; 11: 1451-1468.

65. Markets Insider. Copper price today [Internet]. New York: Insider; 2021. Available from: https://markets.businessinsider.com/commodities/copper-price\#.

66. Daily Metal Prices. Daily metal spot prices, iron ore price (USD/Metric Ton) for the last month [Internet]. Winnipeg: Daily Metal Prices; 2021. Available from: https://www.dailymetalprice.com/metalprices.php?c=fe\&amp;u=kg\&amp;d=1.

67. Kates RW, Colten CE, Laska S, Leatherman SP. Reconstruction of New Orleans after Hurricane 
Katrina: A research perspective. Proc Natl Acad Sci USA. 2006; 103: 14653-14660.

68. Jones CE, An K, Blom RG, Kent JD, Ivins ER, Bekaert D. Anthropogenic and geologic influences on subsidence in the vicinity of New Orleans, Louisiana. J Geophys Res Solid Earth. 2016; 121: 38673887.

69. Louisiana Department of Environmental Quality. Comprehensive plan for disaster clean-up and debris management [Internet]. Baton Rouge: Louisiana Department of Environmental Quality; 2020. Available from: https://deq.louisiana.gov/assets/docs/SolidWaste/DebrisManagementPlanrevised093021.pdf.

70. Louisiana Department of Environmental Quality. Drop off programs for E-Recycling [Internet]. Baton Rouge: Louisiana Department of Environmental Quality; 2013. Available from: https://www.deq.louisiana.gov/page/recycling.

71. Luther LG, Resources S, Division I. Disaster debris removal after Hurricane Katrina: Status and associated issues. Washington: Congressional Research Service, the Library of Congress; 2006.

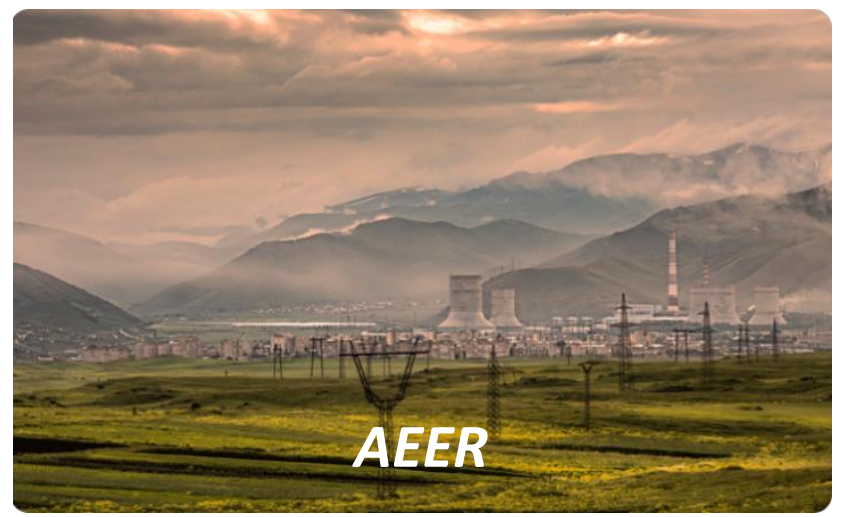

Enjoy $A E E R$ by:

1. Submitting a manuscript

2. Joining in volunteer reviewer bank

3. Joining Editorial Board

4. Guest editing a special issue

For more details, please visit:

http://www.lidsen.com/journals/aeer 